\title{
Adherence to food-based dietary guidelines and evaluation of nutrient intake in 7-year-old children
}

\author{
Asa Gudrun Kristjansdottir and Inga Thorsdottir* \\ Unit for Nutrition Research, Landspitali-University Hospital and Faculty of Food Science and Human Nutrition, \\ University of Iceland, Reykjavik, Iceland
}

Submitted 30 December 2008: Accepted 15 June 2009: First published online 6 August 2009

\begin{abstract}
Objective: To evaluate the diet of 7-year-old children by comparison with foodbased dietary guidelines (FBDG) and reference values for nutrient intake.

Design: Food and nutrient intake was assessed by $3 \mathrm{~d}$ weighed dietary records of 7-year-olds in six randomly chosen schools in Reykjavik, Iceland. Height and weight were measured. The diet of 165 children (62\% of sample) was evaluated by the Icelandic FBDG and the Nordic reference values (NRV) for nutrient intake.

Setting: Six randomly chosen schools in Reykjavik, Iceland.

Results: The FBDG on fruits and vegetables was reached by less than $20 \%$ of the children. A total of $52 \%$ reached the FBDG to eat fish twice a week and $41 \%$ to use vitamin D supplement. The FBDG on dairy was reached by $66 \%$ of the children. Mean intake of SFA gave $13.9 \%$ of the total energy intake (E\%), which is higher than the NRV, $9 \cdot 3 \mathrm{E} \%$ of MUFA and $3 \cdot 8 \mathrm{E} \%$ of PUFA, both lower than the NRV (for all differences $P<0 \cdot 001$ ). Added sugar gave $12 \cdot 1 \mathrm{E} \%$, which exceeds the upper level $(P<0 \cdot 001)$. Fibre intake was $2 \cdot 1 \mathrm{~g} / \mathrm{MJ}$ and lower than the NRV $(P<0 \cdot 001)$. Mean intake of micronutrients was above the recommended intake (RI), except for iodine, $109 \cdot 0 \mu \mathrm{g} / \mathrm{d}$, and vitamin $\mathrm{D}, 6 \cdot 1 \mu \mathrm{g} / \mathrm{d}$, which was lower than the RI $(P=0.006$ and $P<0 \cdot 001$, respectively).

Conclusions: Fruit, vegetable, fish and dairy, as well as vitamin D supplement, need to be increased in the diet of 7-year-old children to reach the FBDG and the reference values for nutrient intake. Dietary changes to increase the quality of fat and carbohydrate are needed as well.
\end{abstract}

\author{
Keywords \\ Schoolchildren \\ Food-based dietary guidelines \\ Nutrient intake
}

Food-based dietary guidelines (FBDG) are promoted worldwide as an important part of national food and nutrition policies ${ }^{(1)}$. Effective implementation of FBDG is needed to contribute to halting the current non-communicable disease epidemic, such as CVD and obesity ${ }^{(2)}$. The prevalence of obesity in childhood has increased worldwide in recent decades ${ }^{(3-6)}$ along with changes in food availability and dietary habits, which also seem to have resulted in diminishing differences in food habits between European countries ${ }^{(7)}$.

The Nordic countries have collaborated for several decades in setting reference values for nutrient intake, which constitute a scientific basis for the $\mathrm{FBDG}^{(8)}$. The recommended intake (RI) of vitamin D in Iceland is higher than in the other Nordic countries, which is based on the risk of vitamin $\mathrm{D}$ deficiency because of the latitude of the country $^{(8-10)}$. Traditionally, vitamin D is supplemented in the form of fish-liver oil, which is also rich in long-chain $n$ - 3 fatty acids. Some of the characteristics of the Icelandic diet have changed in recent decades. Studies from the Unit for
Nutrition Research on diet in childhood have shown that traditionally high fish consumption has decreased; the intake of vitamin D is low, and dairy consumption has decreased as well ${ }^{(11,12)}$. Fruit and vegetable intake is low in Iceland; the intake was lowest in Iceland of the nine European countries participating in the Pro Children cross-sectional study ${ }^{(13)}$.

Few studies have focused, at an individual level, on analysing compliance with FBDG, along with evaluation of nutrient intake by comparison with reference values $^{(14)}$. Dietary habits form during the early school years $^{(15)}$, and healthy food habits acquired in childhood tend to continue into adulthood ${ }^{(16)}$. It is therefore important to know how well the dietary habits of children meet the FBDG and the reference values for nutrient intake. The schools are excellent arenas for reaching a large segment of the population and therefore provide an important opportunity to evaluate children's food habits. The objective of the present school-based study was to evaluate the diet of 7-year-old children by comparison with FBDG and reference values for nutrient intake. 


\section{Methods}

\section{Study population}

The data were collected from September to the end of November 2006, in six randomly selected schools in Reykjavik. The schools were randomly chosen and represented different social backgrounds (living areas). The sample is representative for the greater Reykjavik area, representing $6 \%$ of all children in the second grade in Iceland in 2006. All children in the second grade (born 1999) were invited to participate in a baseline study prior to a planned schoolbased intervention for 7-9-year-old children. At each school, data were collected for 2 weeks. Letters to the parents were circulated, with information on the study goal and procedures and securing written consent, of both parent and child. Parents were invited to meetings in the school the week before the data collection period started. In these meetings, instructions on how to record the diet were given. Of the 265 children invited to participate in the present study, 216 returned food records (82\%).

Ethical approval for the study was obtained from the Icelandic Research Ethics Committee.

\section{Dietary assessment}

The records were continuous over three days, two weekdays and one weekend day. Parents were provided with accurate electronic scales (PHILIPS HR 2393, Hungary; design and quality of Philips Holland). Parents were advised to record all food and drink as well as vitamin supplements. Parents recorded intake for the weekend day, and on weekdays included what the children brought with them to eat in the morning break at school. The school meal was recorded for each child by a trained nutritionist. All intakes were weighed, except standard portion sizes which were used for the school meals, adjusted for leftovers and refills for each child. The food records were entered, coded and checked by nutritionists. Incomplete records and records of less than three days were excluded, leaving 187 complete records for data analysis (71\%).

Records where energy intake (EI) was less than the estimated BMR times 1.2 were classified as under-reports, as evidence has shown that this indicates gross underreporting ${ }^{(17)}$. The equations from the Nordic Nutrition Recommendations $(\mathrm{NNR})^{(8)}$ for calculating the average BMR $(\mathrm{MJ} / \mathrm{d})=$ basal energy expenditure (BEE, $\mathrm{MJ} / \mathrm{d})$ for 4-10-year-old children, based on body weight (W, kg) and height $(\mathrm{H}, \mathrm{m})$, were used: $\mathrm{BMR}_{\text {girls }}=0 \cdot 071 \mathrm{~W}+0 \cdot 68 \mathrm{H}+$ 1.55 and $\mathrm{BMR}_{\text {boys }}=0 \cdot 082 \mathrm{~W}+0.55 \mathrm{H}+1 \cdot 74$. In overweight children the weight was defined to be within the international cut-off points for BMI for overweight ${ }^{(18)}$.

\section{Food-based dietary guidelines}

The FBDG, for adults and children from 2 years of age, implemented by the Public Health Institute of Iceland are:

- Five portions of fruits and vegetables, corresponding to $500 \mathrm{~g} / \mathrm{d}$ for adults; children younger than 10 years require smaller portions. In the present study this was defined as $400 \mathrm{~g}$ of fruits and vegetables or more per day, $200 \mathrm{~g}$ fruits and $200 \mathrm{~g}$ vegetables.

- Fish at least twice a week or at least $300 \mathrm{~g} /$ week. Because of the young age of the children in the present study, the FBDG for fish was defined as at least $240 \mathrm{~g} /$ week.

- Fish-liver oil or another vitamin D supplement, especially during the winter; $5 \mathrm{ml}$ of cod-liver oil gives the RI of vitamin D for children and adults up to 60 years of age. The present study also assessed how many of the children took fish-liver oil some of the days in the $3 \mathrm{~d}$ weighed dietary records.

- Two glasses of milk or another milk product, corresponding to $500 \mathrm{~g}$ per day; products low in fat and added sugar are advised. Cheese can also be used as a source of calcium: $25 \mathrm{~g}$ of cheese corresponding to one glass (one portion) of milk. The recommendation of moderate milk intake was defined as $1 \frac{1}{2}-3 \frac{1}{2}$ portions.

\section{Reference values for evaluation of nutrient intake}

The Nordic reference values (NRV) for macronutrient intake for adults and children (from 2 years of age) were used for evaluating the macronutrient intake. The NRV for micronutrient intake for 6-9-year-olds ${ }^{(8)}$ served as a base for the evaluation of micronutrient intake. The average requirement $(\mathrm{AR})$ is used to assess the risk of inadequate intake of micronutrients. AR is established for adults in the NNR 2004, but not for children. The AR for the children in the present study were therefore estimated from the Nordic values (as Icelandic children are Nordic) to assess how many children were below the AR. The estimated AR (EAR) were extrapolated from the adult AR, using the approach for extrapolation suggested by the US/Canada Food and Nutrition Board, which is based on a separate consideration of maintenance needs and growth needs ${ }^{(20-22)}$. The formula for extrapolation is $\mathrm{EAR}_{\text {child }}=\mathrm{EAR}_{\text {adult }} \times \mathrm{F}$, where $\mathrm{F}=\left(\mathrm{W}_{\text {child }} / \mathrm{W}_{\text {adult }}\right)^{0.75} \times$ $(1+$ growth factor $)$. The average weight $(\mathrm{W}, \mathrm{kg})$ of the children in the present study, $26 \cdot 3 \mathrm{~kg}$, was used together with the weight of an average healthy adult according to $\mathrm{NNR}^{(8)}$. The growth factor, $0 \cdot 15$, for children aged 3 years and older is a value obtained from the proportional increase in protein requirements ${ }^{(19-21)}$. The reference values for micronutrient intake were compared with the US reference values for 4-8-year-olds ${ }^{(22)}$.

\section{Data analysis}

Nutrient calculations were performed on ICEFOOD (program of the Icelandic Nutrition Council), using the Icelandic Nutrient Database (revised), as well as the Icelandic Nutrition Council Recipe Database 2002. All foods and drinks were included in the data analysis; cod-liver oil was included in the data analysis but not other vitamin supplements. Vitamin supplements (other than fish-liver oil) were used some of the days in the $3 \mathrm{~d}$ dietary record 
by $22 \%$ of the children (36 of the 165); approximately $11 \%$ took a vitamin supplement, including vitamin D.

All statistical analyses were carried out using SPSS (Statistical Package for the Social Sciences) for Windows, version $11 \cdot 0$. The level of significance used was $P<0 \cdot 05$. Food and nutrient intakes were checked for normality by inspection and by using the Kolmogorov-Smirnov test. The intake distribution of some nutrients was skewed and was transformed to a natural logarithm prior to statistical analysis. A non-parametric test (Mann-Whitney $U$ ) was used to identify gender differences for food intake, as there were some zero values. An independent samples $t$-test was used to identify gender differences for nutrient intake. A one-sided $t$-test was used to assess whether a difference between the intake of nutrient and the reference value was significant. An independent samples $t$-test was used to compare the macronutrient intake on weekend days, Saturday and Sunday, against weekdays. An independent samples $t$-test was used to compare nutrient intake for the children reaching the FBDG $v$. those not reaching the FBDG; ANOVA for the FBDG on milk (in Figs 1-4).

\section{Results}

Height and weight were measured in 265 children. The 187 children included in the analysis did not differ from the seventy-eight children not included with regard to BMI $(P=0 \cdot 795)$. Under-reporters (eleven girls and eleven boys) were excluded in the data analysis, leaving eighty-nine girls and seventy-six boys for the evaluation of intake.
The under-reporters had higher BMI than those not underreporting, $17 \cdot 5 \mathrm{~kg} / \mathrm{m}^{2} v \cdot 16 \cdot 1 \mathrm{~kg} / \mathrm{m}^{2}(P=0 \cdot 016)$.

Table 1 shows the mean food intake $(\mathrm{g} / \mathrm{d})$, separately for girls and boys. The mean intake of fruit and vegetables was lower than recommended, especially the vegetable intake. The most consumed fruits were apples, bananas and oranges. The most consumed vegetables were raw cucumbers, carrots and tomatoes, and less was consumed of other raw and cooked vegetables. Fish intake as well as fish-liver oil intake were lower than recommended. The most consumed fish was lean fish, such as haddock and cod. The mean intakes of processed fish and processed meat were about $3 \mathrm{~g} / \mathrm{d}$ and less than $10 \mathrm{~g} / \mathrm{d}$, respectively; processed fish and meat are not included in the table as the proportion of fish and meat in processed products is relatively low. The intake of fish and fish-liver oil was significantly higher for boys than girls. There was no significant difference between genders in the intake of other food groups. Table 2 shows the percentage of children meeting the FBDG. In total, $16 \%$ reached the FBDG to eat at least $200 \mathrm{~g}$ of fruit/d and $1 \%$ to eat at least $200 \mathrm{~g}$ of vegetables/d. Further, $52 \%$ reached the FBDG to eat fish twice a week and $41 \%$ took fish-liver oil some of the recording days or reached the FBDG for intake of $5 \mathrm{ml}$ of fish-liver oil/d. In total, $66 \%$ of the children reached the FBDG on dairy intake, $1 \frac{1}{2}-3 \frac{1}{2}$ portions of milk or other milk products per day, $26 \%$ consumed less than $1 \frac{1}{2}$ portions and $8 \%$ more than $3 \frac{1}{2}$ portions.

Table 3 shows the mean macronutrient intake per day, the 25 th and the 75 th percentiles and the NRV. The mean energy from SFA was higher than the NRV. The mean energy intake from the unsaturated fatty acids, MUFA

Table 1 Mean intake $(\mathrm{g} / \mathrm{d})$ of 7-year-old girls ( $n$ 89) and boys ( $n$ 76)

\begin{tabular}{|c|c|c|c|c|c|}
\hline \multirow[b]{2}{*}{ Food group } & \multicolumn{2}{|c|}{ Girls } & \multicolumn{2}{|c|}{ Boys } & \multirow[b]{2}{*}{$P$ (absolute intake) } \\
\hline & Mean $(g / d)$ & SD & Mean $(g / d)$ & SD & \\
\hline Fruit total (fresh fruits) & $140 \cdot 6$ & $99 \cdot 4$ & $124 \cdot 0$ & $100 \cdot 1$ & $0 \cdot 181$ \\
\hline Raw vegetables & $31 \cdot 3$ & $39 \cdot 1$ & $35 \cdot 0$ & $40 \cdot 0$ & 0.475 \\
\hline Cooked vegetables & $6 \cdot 3$ & $13 \cdot 3$ & $8 \cdot 6$ & $14 \cdot 5$ & 0.364 \\
\hline Vegetables total $^{*}$ & $37 \cdot 6$ & $39 \cdot 3$ & $43 \cdot 6$ & $41 \cdot 2$ & 0.328 \\
\hline Fruit and vegetables & $178 \cdot 3$ & $115 \cdot 7$ & $167 \cdot 6$ & $110 \cdot 2$ & 0.438 \\
\hline Fisht & $14 \cdot 5$ & $17 \cdot 7$ & $22 \cdot 5$ & $24 \cdot 2$ & 0.030 \\
\hline Fish-liver oil & $1 \cdot 0$ & $1 \cdot 8$ & 1.9 & $2 \cdot 6$ & 0.029 \\
\hline Milk and cocoa milkł & $264 \cdot 6$ & $154 \cdot 7$ & $307 \cdot 3$ & $179 \cdot 4$ & $0 \cdot 141$ \\
\hline Fermented milk products $\ddagger$ & $108 \cdot 3$ & $97 \cdot 2$ & $115 \cdot 4$ & $120 \cdot 4$ & 0.924 \\
\hline Cheese & $12 \cdot 8$ & $13 \cdot 4$ & $11 \cdot 3$ & $12 \cdot 7$ & 0.512 \\
\hline Meatt & $57 \cdot 3$ & $36 \cdot 8$ & $56 \cdot 1$ & $32 \cdot 6$ & $0 \cdot 848$ \\
\hline Bread & $66 \cdot 8$ & $41 \cdot 9$ & $67 \cdot 7$ & $39 \cdot 2$ & 0.688 \\
\hline Breakfast cereal & $33 \cdot 8$ & $23 \cdot 3$ & $42 \cdot 6$ & $31 \cdot 4$ & 0.079 \\
\hline Biscuit and cakes & $48 \cdot 9$ & $44 \cdot 1$ & $49 \cdot 5$ & $52 \cdot 3$ & 0.583 \\
\hline Chips and French fries & $13 \cdot 7$ & $19 \cdot 2$ & $13 \cdot 0$ & $20 \cdot 9$ & 0.432 \\
\hline Fruit juice (100\% pure) & $78 \cdot 0$ & $84 \cdot 8$ & $90 \cdot 4$ & $113 \cdot 7$ & 0.950 \\
\hline Sweetened beverages $\S$ & $104 \cdot 8$ & $114 \cdot 0$ & $104 \cdot 1$ & $124 \cdot 9$ & 0.749 \\
\hline Candy $\|$ & $23 \cdot 2$ & $28 \cdot 1$ & $17 \cdot 0$ & $20 \cdot 8$ & $0 \cdot 182$ \\
\hline
\end{tabular}

$P$-values shown for difference, significant differences in bold.

*Potatoes are not included in 'vegetables'.

tProcessed fish (fish fingers and fish cakes) and meat (forcemeat, hot dogs, etc.) are not included in these values.

‡Not including milk products in other food items.

§Including sweetened fruit drinks.

IIIncluding chocolate and other sweets. 
Table 2 Percentage of children reaching the food-based dietary guidelines (in bold), and the distribution of intake for some of the food groups, analysed for girls ( $n$ 89) and boys ( $n$ 76), separately

\begin{tabular}{|c|c|c|c|c|c|}
\hline \multirow[b]{2}{*}{ Food group } & \multirow[b]{2}{*}{ Measure } & \multicolumn{2}{|c|}{ Girls } & \multicolumn{2}{|c|}{ Boys } \\
\hline & & $n$ & $\%$ & $n$ & $\%$ \\
\hline \multirow[t]{3}{*}{ Fresh fruits } & $<150 \mathrm{~g} / \mathrm{d}$ & 53 & $59 \cdot 6$ & 51 & $67 \cdot 1$ \\
\hline & $150-200 \mathrm{~g} / \mathrm{d}$ & 21 & $23 \cdot 6$ & 14 & $18 \cdot 4$ \\
\hline & $\geq 200 \mathrm{~g} / \mathrm{d}$ & 15 & $16 \cdot 9$ & 11 & $14 \cdot 5$ \\
\hline \multirow[t]{3}{*}{ Vegetables* } & $<150 \mathrm{~g} / \mathrm{d}$ & 87 & $97 \cdot 8$ & 74 & $97 \cdot 4$ \\
\hline & $150-200 \mathrm{~g} / \mathrm{d}$ & 1 & $1 \cdot 1$ & 2 & $2 \cdot 6$ \\
\hline & $\geq 200 \mathrm{~g} / \mathrm{d}$ & 1 & $1 \cdot 1$ & 0 & 0.0 \\
\hline \multirow[t]{2}{*}{ Fisht } & Twice a week & 41 & $46 \cdot 1$ & 45 & $59 \cdot 2$ \\
\hline & $\geq 240 \mathrm{~g} /$ week & 9 & $10 \cdot 1$ & 23 & $30 \cdot 3$ \\
\hline \multirow[t]{2}{*}{ Fish-liver oil } & Take it some days $\ddagger$ & 31 & $34 \cdot 8$ & 36 & $47 \cdot 4$ \\
\hline & $\geq 5 \mathrm{ml} / \mathrm{d}(\leq 10 \mathrm{ml} / \mathrm{d})$ & 5 & $5 \cdot 6$ & 16 & $21 \cdot 0$ \\
\hline \multirow[t]{3}{*}{ Milk and milk products $\S$} & $<1 \frac{1}{2}$ portions/d & 26 & $29 \cdot 2$ & 17 & $22 \cdot 4$ \\
\hline & $1 \frac{1}{2}-3 \frac{1}{2}$ portions/d & 57 & $64 \cdot 0$ & 52 & $68 \cdot 4$ \\
\hline & $>3 \frac{1}{2}$ portions $/ d$ & 6 & $6 \cdot 7$ & 7 & $9 \cdot 2$ \\
\hline
\end{tabular}

*Potatoes are not included in 'vegetables'.

tProcessed fish (fish fingers and fish cakes) are not included in these values.

¥'Take it some days' means that the children took fish-liver oil some of the recording days.

$\S$ Milk and other milk products, including cheese, $25 \mathrm{~g}$ of cheese corresponding to one portion of milk ( $250 \mathrm{~g}$, one glass), not including milk products in other food items.

Table 3 Mean intake of macronutrients per day (SD), 25th and 75th percentiles and the Nordic reference values for adults and children from 2 years of $\operatorname{age}^{(8)}(n 165)$

\begin{tabular}{|c|c|c|c|c|c|}
\hline \multirow[b]{2}{*}{ Macronutrients } & \multirow[b]{2}{*}{ Mean } & \multirow[b]{2}{*}{ SD } & \multicolumn{2}{|c|}{ Percentiles } & \multirow[b]{2}{*}{ Nordic reference values } \\
\hline & & & 25th & 75th & \\
\hline Energy (kJ) & 7257 & 1327 & 6257 & 8111 & \\
\hline Energy (kcal) & 1734 & 317 & 1496 & 1939 & \\
\hline Total fat (E\%) & $31 \cdot 8$ & $4 \cdot 8$ & $28 \cdot 5$ & $34 \cdot 7$ & $30(25-35)$ \\
\hline SFA (E\%) & $13 \cdot 9$ & $2 \cdot 6$ & $12 \cdot 2$ & $15 \cdot 4$ & $\leq 10$ \\
\hline MUFA (E\%) & $9 \cdot 3$ & $1 \cdot 8$ & $7 \cdot 9$ & $10 \cdot 4$ & $10-15$ \\
\hline PUFA (E\%) & $3 \cdot 8$ & $1 \cdot 2$ & $3 \cdot 0$ & $4 \cdot 4$ & $5-10$ \\
\hline$n-6$ PUFA (E\%) & $2 \cdot 8$ & $1 \cdot 0$ & $2 \cdot 2$ & $3 \cdot 2$ & $4(-9)$ \\
\hline$n-3$ PUFA (E\%) & $0 \cdot 8$ & 0.3 & $0 \cdot 6$ & $1 \cdot 0$ & About 1 \\
\hline$n-6 / n-3$ & $3 \cdot 8$ & $1 \cdot 4$ & $2 \cdot 9$ & 4.9 & 4-9 considered adequate \\
\hline Total carbohydrate (E\%) & $52 \cdot 1$ & $5 \cdot 1$ & $48 \cdot 2$ & $55 \cdot 3$ & $55(50-60)$ \\
\hline Added sugar (E\%) & $12 \cdot 1$ & $4 \cdot 7$ & $9 \cdot 1$ & $14 \cdot 9$ & $<10$ \\
\hline Fibre $(\mathrm{g})$ & $14 \cdot 8$ & $3 \cdot 6$ & $12 \cdot 2$ & $17 \cdot 3$ & $25-35$ for adults \\
\hline Fibre (g/MJ) & $2 \cdot 1$ & 0.5 & $1 \cdot 8$ & $2 \cdot 4$ & 3 \\
\hline Protein $(\mathrm{g})$ & $67 \cdot 9$ & $14 \cdot 4$ & $57 \cdot 1$ & $79 \cdot 6$ & \\
\hline Protein $(\mathrm{E} \%)$ & $16 \cdot 1$ & $2 \cdot 5$ & $14 \cdot 4$ & $17 \cdot 9$ & $15(10-20)$ \\
\hline Protein (g/kg body weight) & $2 \cdot 6$ & 0.6 & $2 \cdot 2$ & $3 \cdot 0$ & \\
\hline
\end{tabular}

$\mathrm{E} \%$, percentage of total energy intake.

Added sugar includes only sugars eaten separately at the table and sugars used as an ingredient in processed or prepared foods, but not naturally occurring sucrose in fruits and berries.

and PUFA, was lower than the NRV. Mean energy intake from added sugar was higher than the upper level of intake. Added sugar included only sugars eaten separately at the table and sugars used as an ingredient in processed or prepared foods, but not naturally occurring sucrose in fruits and berries. The intake of fibre was lower than the NRV. Other macronutrients were within recommendations.

Mean energy intake was higher on weekends, Saturday and Sunday, than on weekdays $(P=0 \cdot 049)$. Mean protein intake was higher on weekdays than on weekends $(P<0 \cdot 001)$. Mean fat intake was similar on weekends and weekdays $(P=0 \cdot 486)$. Mean carbohydrate and added sugar intakes were higher on weekends than on weekdays ( $P=0 \cdot 001$ and $P<0 \cdot 001$, respectively).
The mean intake was above the Nordic RI for most of the micronutrients, except for vitamin $\mathrm{D}$ and iodine (Table 4). To assess the risk of inadequate intake of micronutrients, the intake was compared with AR for the children, which in the present study were estimated from the Nordic AR for adults. Table 4 shows the estimated AR for the present study and the percentage of children with micronutrient intake below the estimated AR. The percentage of children with micronutrient intake below the US EAR (Estimated Average Requirement) is also shown for comparison.

Figure 1 shows the mean intake of $n$ - 3 fatty acids for the children taking fish-liver oil some of the days in the $3 \mathrm{~d}$ dietary record $v$. those who did not. Figure 2 shows 


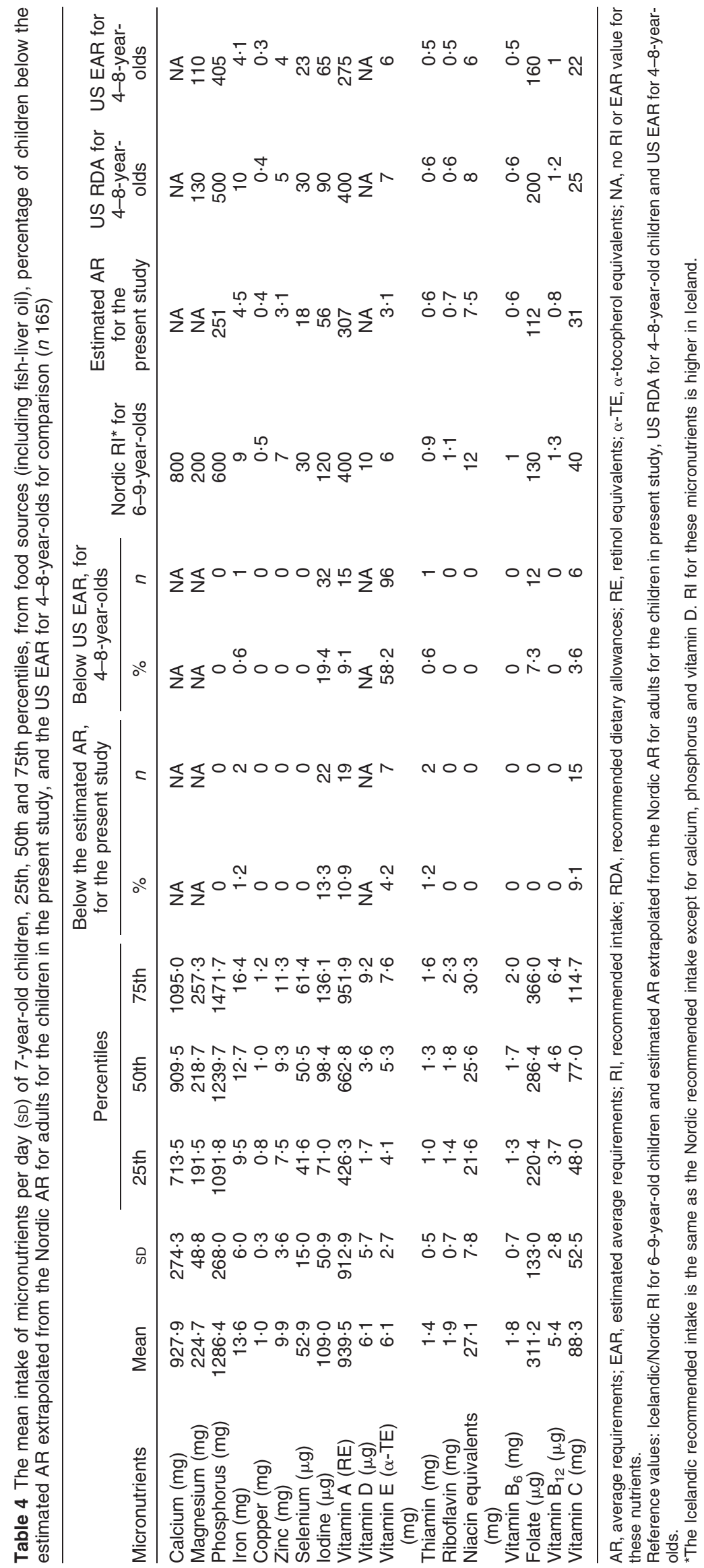




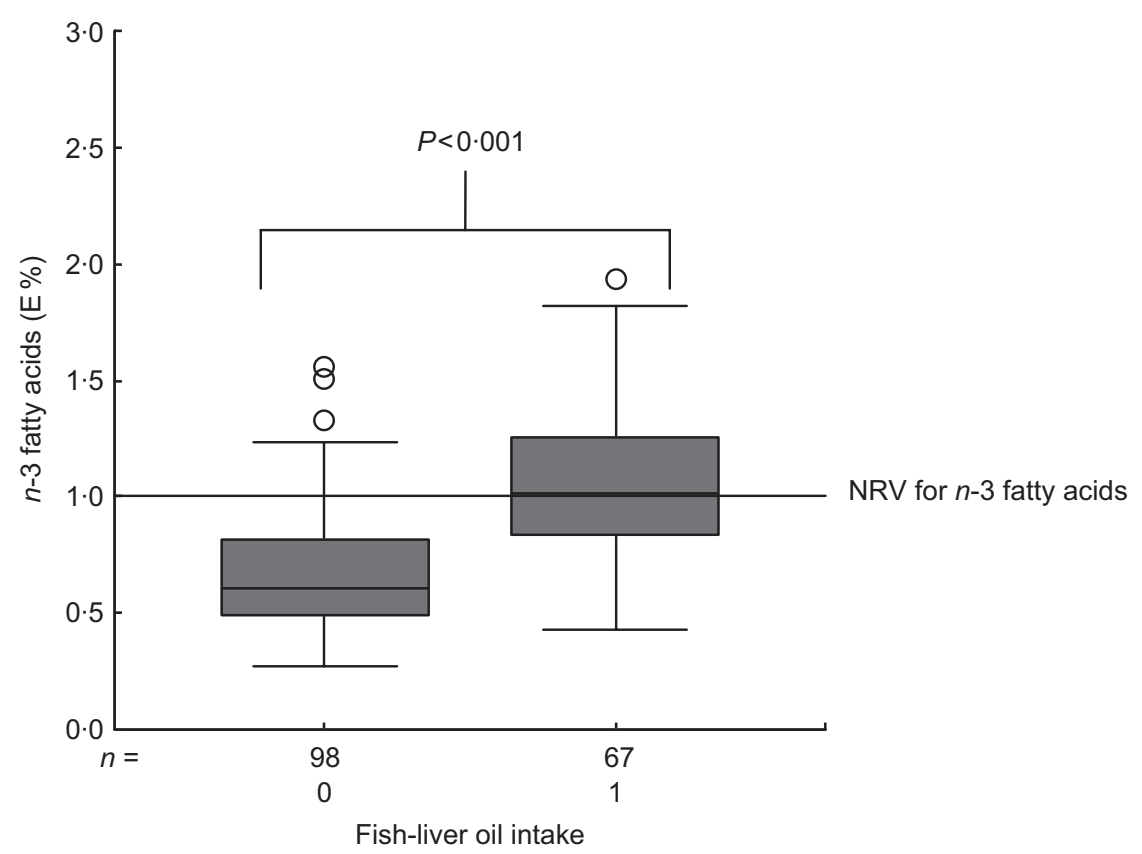

Fig. 1 The mean intake of $n-3$ fatty acids (percentage of total energy intake, E\%) for the children who took fish-liver oil some of the recording days (1) $v$. those who did not take it (0), and the Nordic reference value (NRV) for $n-3$ fatty acids. The mean intake of $n$-3 fatty acids for those taking fish-liver oil was 1.0E\%, similar to the NRV (about 1E\%), but the intake was lower for those not taking fish-liver oil $(0 \cdot 7 \mathrm{E} \%)$

the mean calcium intake for the children reaching the FBDG on milk $v$. those not reaching the FBDG. The main source of calcium in the children's diet was milk and milk products. The main iodine source in the children's diet was fish, milk and milk products. Figure 3 shows the mean iodine intake among the children reaching the FBDG on fish $v$. those not reaching the FBDG. Figure 4 shows the mean intake of iodine for children reaching the FBDG, $1 \frac{1}{2}-3 \frac{1}{2}$ portions, on milk $v$. those consuming less or more.

Table 5 shows the mean intake of macro- and micronutrients separately for girls and boys. Boys had significantly higher intake of proteins, $n-3$ fatty acids, calcium, phosphorus, selenium, iodine, vitamin D, vitamin $\mathrm{E}$ and niacin equivalents. When nutrient density was compared, fewer differences were apparent; boys still had significantly higher intake of $n$ - 3 fatty acids, calcium, phosphorus and vitamin D than girls. The percentage of energy from carbohydrates was higher for girls than boys.

\section{Discussion}

The results of the present study indicate that the diet of a large group of 7-year-old children was, late in 2006, far from the FBDG set for the Icelandic population. Few children met the recommendation to eat at least $200 \mathrm{~g}$ of fruit/d and fewer still to eat at least $200 \mathrm{~g}$ of vegetables/d. About half of the children reached the recommendation to eat fish at least twice a week. Fewer reached the recommendation to use fish-liver oil. Two-thirds of the children reached the milk recommendation.

The method selected in the present study was $3 \mathrm{~d}$ weighed dietary records; it was completed by the parents because of the young age of the children, and the school meal recorded by the researchers at school. The method selected has a relatively high respondent burden, which may have affected the participation rate. However, $82 \%$ of the sample returned the $3 \mathrm{~d}$ dietary records, and $71 \%$ of the sample completed the records. Three-day dietary records give an accurate estimate of usual intake for most frequently used foods; for intake of occasionally used foods more days are required, but the respondent burden would then have been higher. Validation studies of energy intake have led to the widespread recognition that dietary data on children and adolescents are prone to reporting error, mostly through under-reporting ${ }^{(23)}$. Evaluating the validity of reported energy intake provides a valuable check on the general quality of the dietary data ${ }^{(24)}$. Reported energy intakes were evaluated using the estimated BEE of the children. Under-reporters were excluded from the analysis. The mean energy intake in the present study was similar to the mean energy intake of children of the same age range in other studies ${ }^{(25,26)}$.

The low consumption of fruits and vegetables is in line with other studies of the diet of Icelandic children ${ }^{(12,27,28)}$. The low fruit and vegetable consumption and low intake of whole-grain products results in dietary fibre intake below the NRV ( $3 \mathrm{~g} / \mathrm{MJ})$. To increase the intake of fibre, the intake of whole-grain products, such as wholemeal 


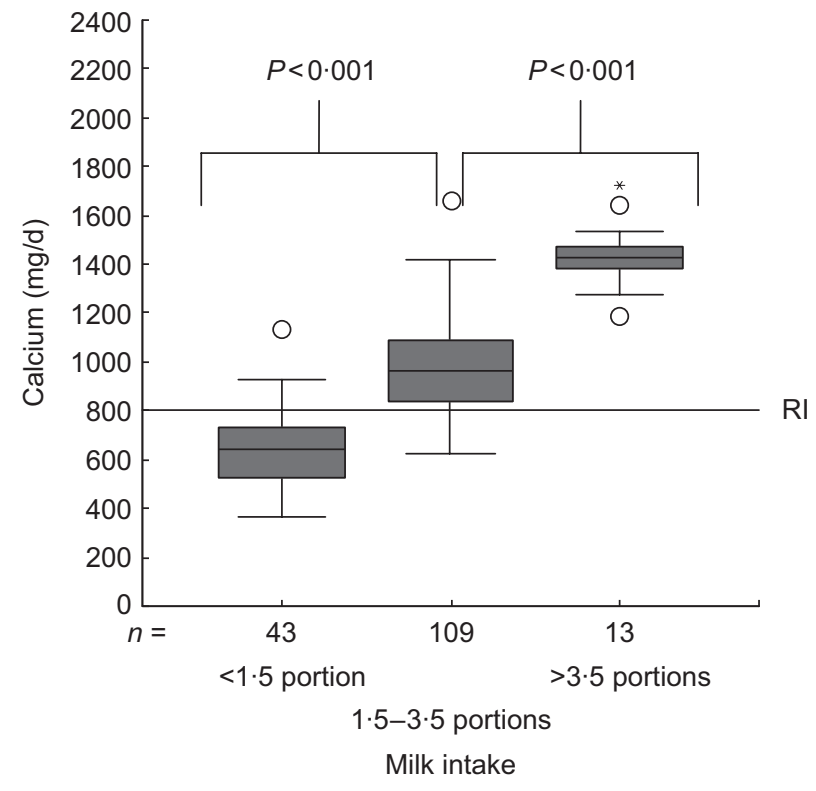

Fig. 2 Mean intake of calcium for the children reaching the food-based dietary guidelines (FBDG) on milk, i.e. had intake around two portions/d (1.5-3.5 portions/d) $v$. those who had lower or higher intake and the Icelandic recommended intake (RI) for calcium. One portion corresponds to $250 \mathrm{~g}$ of milk and other milk products, including cheese, $25 \mathrm{~g}$ of cheese corresponding to one portion. The mean calcium intake for the children reaching the FBDG on milk intake was $974 \mathrm{mg} / \mathrm{d}$, which is above the Icelandic RI $(800 \mathrm{mg} / \mathrm{d})$. The mean intake was lower among those consuming less than $1 \frac{1}{2}$ portions $(658 \mathrm{mg} / \mathrm{d})$

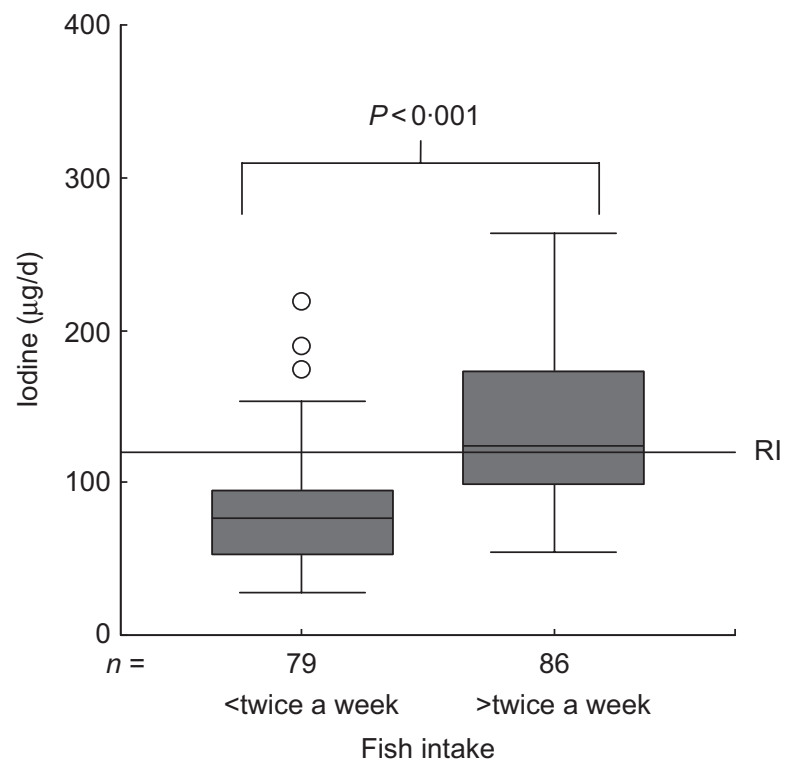

Fig. 3 Mean intake of iodine for those reaching the food-based dietary guidelines (FBDG) on fish, i.e. to eat fish twice a week or more often $v$. those who did not reach the FBDG and the Nordic recommended intake $(\mathrm{RI})$ for iodine. The mean iodine intake among the children reaching the FBDG on fish was $135 \mu \mathrm{g} / \mathrm{d}$, which is above the Nordic RI $(120 \mu \mathrm{g} / \mathrm{d})$. It was lower for those not reaching the FBDG $(80 \mu \mathrm{g} / \mathrm{d})$

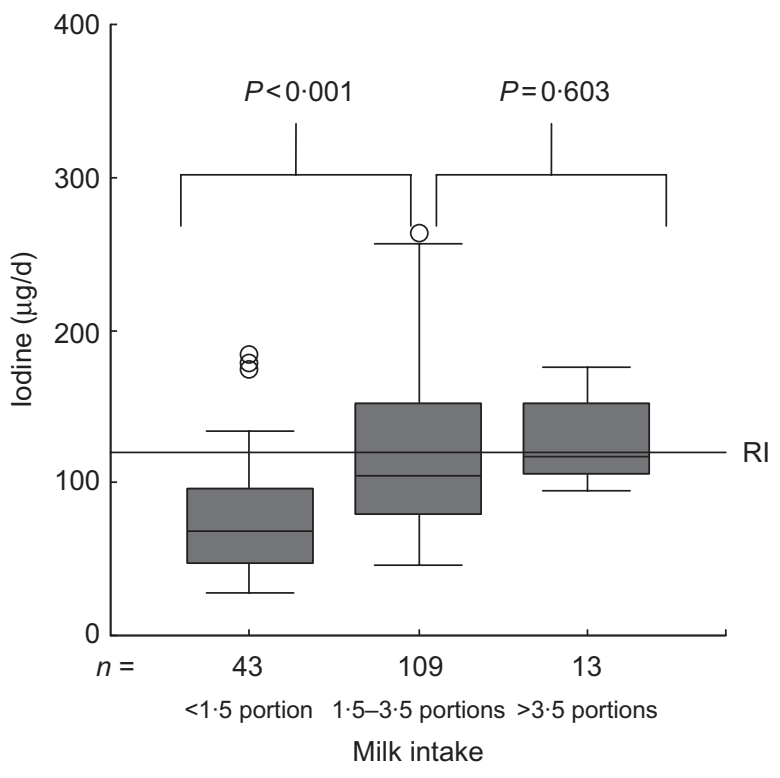

Fig. 4 Mean intake of iodine for the children reaching the foodbased dietary guidelines (FBDG) on milk, i.e. with intake around two portions/d (1.5-3.5 portions/d) v. those with lower or higher intake and the Nordic recommended intake (RI) for iodine. One portion corresponds to $250 \mathrm{~g}$ of milk and other milk products, including cheese, $25 \mathrm{~g}$ of cheese corresponding to one portion. The mean intake of iodine for children reaching the FBDG on milk was $119 \mu \mathrm{g} / \mathrm{d}$, which is similar to the Nordic RI $(120 \mu \mathrm{g} / \mathrm{d})$. Intake was lower for those consuming less than $1 \frac{1}{2}$ portions and higher for those consuming more than $3 \frac{1}{2}$ portions

breads, fruits and vegetables, needs to be increased. The fibre content of most of the breads available in Iceland is below the recommendation ( $>6 \mathrm{~g}$ fibre $/ 100 \mathrm{~g}$ ). Economic factors may also affect the consumption of wholemeal breads as they are usually more expensive, and studies in the UK and the USA have found that greater consumption of whole grains tends to be associated with higher socioeconomical status of the household ${ }^{(29-31)}$. Increasing fruit and vegetable intake might also have the effect of decreasing sugar intake, which was higher than the upper level for intake ( $<10 \%$ of the energy from added sugars). A Norwegian study found a negative association between fruit and vegetable intake and sugar intake among children $^{(32)}$. The intake of added sugar was higher on weekends than on weekdays. Weekends may have less structured food choices and mealtimes, compared with weekdays. There are few studies on the possible difference in intake between weekend and weekdays, especially for children. A study from the USA found a difference in energy intake between the weekdays and weekends ${ }^{(33)}$, as was found in the present study. Elementary schools' food policy may contribute to the lower intake of added sugar during the weekdays, as children are not allowed to bring sweets or soft drinks to school. Many shops offer a $50 \%$ reduction on the price of candy bars on Saturdays, sometimes called 'candy day', which may affect the sugar intake on weekends. The mean intake of biscuits and cakes was 
Table 5 Mean nutrient intake per day (SD) and the percentage contributed to energy intake from macronutrients $(n$ 165)

\begin{tabular}{|c|c|c|c|c|c|c|}
\hline \multirow[b]{2}{*}{ Dietary constituent } & \multicolumn{2}{|c|}{ Girls ( $n$ 89) } & \multicolumn{2}{|c|}{ Boys ( $n 76)$} & \multirow[b]{2}{*}{$P$ (absolute intake) } & \multirow[b]{2}{*}{$P$ (nutrient density) } \\
\hline & Mean & SD & Mean & SD & & \\
\hline Energy (kJ) & $7137 \cdot 1$ & 1328 & $7396 \cdot 8$ & 1321 & $0 \cdot 211$ & \\
\hline Energy (kJ/kg body weight) & 279.5 & $55 \cdot 1$ & $284 \cdot 8$ & $52 \cdot 1$ & 0.533 & \\
\hline Protein $(g)$ & $65 \cdot 0$ & $12 \cdot 8$ & $71 \cdot 2$ & $15 \cdot 5$ & 0.006 & \\
\hline Energy from protein (\%) & $15 \cdot 8$ & $2 \cdot 4$ & $16 \cdot 5$ & $2 \cdot 5$ & & 0.055 \\
\hline Fat $(\mathrm{g})$ & $59 \cdot 2$ & $15 \cdot 8$ & $62 \cdot 9$ & $14 \cdot 4$ & $0 \cdot 121$ & \\
\hline Energy from fat (\%) & $31 \cdot 3$ & $4 \cdot 8$ & $32 \cdot 3$ & $4 \cdot 7$ & & $0 \cdot 188$ \\
\hline SFA (g) & $26 \cdot 0$ & $7 \cdot 8$ & $27 \cdot 6$ & $7 \cdot 2$ & $0 \cdot 181$ & \\
\hline Energy from SFA (\%) & $13 \cdot 7$ & $2 \cdot 6$ & $14 \cdot 1$ & $2 \cdot 6$ & & 0.300 \\
\hline MUFA (g) & $17 \cdot 2$ & $4 \cdot 6$ & $18 \cdot 4$ & $4 \cdot 7$ & $0 \cdot 101$ & \\
\hline Energy from MUFA (\%) & $9 \cdot 1$ & $1 \cdot 7$ & $9 \cdot 4$ & $1 \cdot 8$ & & 0.236 \\
\hline PUFA (g) & $7 \cdot 0$ & $2 \cdot 5$ & $7 \cdot 5$ & $2 \cdot 7$ & 0.264 & \\
\hline Energy from PUFA (\%) & $3 \cdot 7$ & $1 \cdot 1$ & 3.9 & $1 \cdot 3$ & & 0.467 \\
\hline PUFA $n-6 c^{*}{ }^{*}$ & $5 \cdot 3$ & $1 \cdot 9$ & $5 \cdot 5$ & $2 \cdot 2$ & 0.597 & 0.867 \\
\hline PUFA $n$-3cis & $1 \cdot 4$ & $0 \cdot 6$ & $1 \cdot 7$ & $0 \cdot 7$ & 0.009 & 0.029 \\
\hline$n-6 / n-3$ & 3.9 & $1 \cdot 2$ & $3 \cdot 6$ & 1.5 & $0 \cdot 164$ & \\
\hline Carbohydrate (g) & $225 \cdot 9$ & $47 \cdot 5$ & $227 \cdot 0$ & $48 \cdot 9$ & 0.883 & \\
\hline Energy from carbohydrate (\%) & $52 \cdot 9$ & $5 \cdot 0$ & $51 \cdot 2$ & $5 \cdot 2$ & & 0.032 \\
\hline Added sugar (g) & $54 \cdot 1$ & $25 \cdot 4$ & $52 \cdot 8$ & $23 \cdot 9$ & $0 \cdot 720$ & \\
\hline Energy from added sugar (\%) & $12 \cdot 5$ & $4 \cdot 8$ & $11 \cdot 7$ & $4 \cdot 6$ & & 0.286 \\
\hline Fibre $(g)$ & $15 \cdot 0$ & $3 \cdot 6$ & $14 \cdot 7$ & $3 \cdot 6$ & 0.637 & $0 \cdot 178$ \\
\hline Sodium (mg) & $2424 \cdot 9$ & $522 \cdot 9$ & $2659 \cdot 7$ & 674.9 & 0.013 & 0.091 \\
\hline Potassium (mg) & $2304 \cdot 0$ & $515 \cdot 4$ & $2427 \cdot 5$ & $512 \cdot 6$ & $0 \cdot 126$ & 0.484 \\
\hline $\mathrm{Na} / \mathrm{K}$ ratio & $1 \cdot 1$ & $0 \cdot 3$ & $1 \cdot 1$ & 0.3 & 0.331 & \\
\hline Calcium (mg) & $881 \cdot 2$ & $256 \cdot 3$ & $982 \cdot 6$ & $286 \cdot 1$ & 0.017 & 0.048 \\
\hline Magnesium (mg) & $219 \cdot 8$ & $47 \cdot 8$ & $230 \cdot 4$ & $49 \cdot 7$ & $0 \cdot 163$ & 0.551 \\
\hline Phosphorus (mg) & $1234 \cdot 3$ & $242 \cdot 4$ & $1347 \cdot 4$ & $284 \cdot 8$ & 0.007 & 0.030 \\
\hline Iron (mg) & $13 \cdot 2$ & $5 \cdot 4$ & $14 \cdot 1$ & $6 \cdot 7$ & 0.342 & 0.622 \\
\hline Copper (mg) & $1 \cdot 0$ & $0 \cdot 3$ & $1 \cdot 0$ & $0 \cdot 2$ & 0.396 & 0.587 \\
\hline $\operatorname{Zinc}(\mathrm{mg})^{*}$ & $9 \cdot 7$ & $3 \cdot 7$ & $10 \cdot 2$ & $3 \cdot 5$ & 0.273 & 0.620 \\
\hline Selenium $(\mu \mathrm{g})$ & $50 \cdot 7$ & $12 \cdot 6$ & $55 \cdot 5$ & $17 \cdot 1$ & 0.042 & $0 \cdot 220$ \\
\hline lodine $(\mu \mathrm{g})^{*}$ & $99 \cdot 5$ & $42 \cdot 6$ & $120 \cdot 0$ & $57 \cdot 5$ & 0.026 & 0.088 \\
\hline Retinol $(\mu \mathrm{g})^{*}$ & $826 \cdot 7$ & $851 \cdot 9$ & $878 \cdot 6$ & $975 \cdot 3$ & 0.459 & 0.625 \\
\hline$\beta$-Carotene $(\mu \mathrm{g}) \dagger$ & $993 \cdot 2$ & $1026 \cdot 7$ & $1152 \cdot 5$ & $1152 \cdot 1$ & $0 \cdot 214$ & 0.383 \\
\hline Vitamin $A(R E)(\mu g)^{*}, \ddagger$ & $909 \cdot 5$ & $851 \cdot 6$ & $974 \cdot 6$ & $984 \cdot 4$ & 0.437 & 0.625 \\
\hline Vitamin D $(\mu \mathrm{g})^{*}$ & $4 \cdot 8$ & $4 \cdot 4$ & $7 \cdot 7$ & $6 \cdot 7$ & 0.007 & 0.013 \\
\hline Vitamin $E(\alpha-T E)(m g)^{\star}$ & $5 \cdot 7$ & $2 \cdot 3$ & $6 \cdot 6$ & $3 \cdot 0$ & 0.035 & $0 \cdot 116$ \\
\hline Thiamin (mg) & $1 \cdot 4$ & 0.4 & $1 \cdot 5$ & $0 \cdot 6$ & 0.357 & 0.769 \\
\hline Riboflavin (mg) & $1 \cdot 8$ & $0 \cdot 6$ & $2 \cdot 0$ & $0 \cdot 8$ & 0.048 & $0 \cdot 171$ \\
\hline Niacin equivalents $(\mathrm{mg})^{\star}, \S$ & $25 \cdot 8$ & $6 \cdot 5$ & $28 \cdot 5$ & $9 \cdot 0$ & 0.039 & $0 \cdot 145$ \\
\hline Vitamin $B_{6}(m g)^{*}$ & $1 \cdot 7$ & 0.6 & 1.9 & $0 \cdot 8$ & $0 \cdot 108$ & 0.312 \\
\hline Folate $(\mu \mathrm{g})$ & $304 \cdot 6$ & $129 \cdot 0$ & $318 \cdot 9$ & $138 \cdot 0$ & 0.492 & 0.832 \\
\hline Vitamin $B_{12}(\mu \mathrm{g})^{*}$ & $5 \cdot 2$ & $2 \cdot 7$ & $5 \cdot 6$ & $2 \cdot 9$ & 0.228 & 0.421 \\
\hline Vitamin $C(\mathrm{mg})^{\star}$ & $90 \cdot 6$ & $51 \cdot 0$ & $85 \cdot 6$ & $54 \cdot 4$ & 0.422 & $0 \cdot 246$ \\
\hline
\end{tabular}

RE, retinol equivalents; $\alpha$-TE, $\alpha$-tocopherol equivalents.

$P$-values shown for the difference before and after adjustment for energy, significant differences in bold.

Added sugar includes only sugars eaten separately at the table and sugars used as an ingredient in processed or prepared foods, but not naturally occurring sucrose in fruits and berries.

${ }^{*}$ Transformed to natural logarithm prior to statistical analysis.

$+\beta$-Carotene intake was still skewed after transformation and therefore non-parametric tests were used (Mann-Whitney $U$-test).

$\ddagger$ Retinol equivalents $=$ retinol $+\beta$-carotene/ 12 .

$\S$ Niacin equivalents $=$ niacin + tryptophan $/ 60$.

$50 \mathrm{~g} / \mathrm{d}$ in the present study. In a study in 9-year-olds, where the diet was assessed with repeated $24 \mathrm{~h}$ recalls, the mean intake of biscuits and cakes was $80 \mathrm{~g} / \mathrm{d}^{(12)}$. In a study in 3-5-year-olds, where the diet was assessed with $3 \mathrm{~d}$ estimated dietary records, the intake of biscuits and cakes was $20 \mathrm{~g} / \mathrm{d}$ in 3 -year-olds, and $35 \mathrm{~g} / \mathrm{d}$ in 5 -yearolds ${ }^{(36)}$. The intake of biscuits and cakes seems, therefore, to increase with age.

The energy intake from SFA was higher than the NRV, and the intake of unsaturated fatty acids, MUFA and PUFA, was lower than the NRV. This is similar to what has been found in the other Nordic countries: quite high levels of SFA, with relatively lower levels of both MUFA and PUFA $^{(26)}$. The ratio between the essential n-6 and $n-3$ fatty acids was within the NRV. The children who did not take fish-liver oil, however, had intake of $n-3$ fatty acids below the NRV for $n-3$ fatty acids. The ratio has been relatively low in Iceland, compared to the other Nordic countries $^{(8)}$, because of the high fish consumption and the use of fish-liver oil, and the low intake of $n-6$ fatty acids.

To identify how many children were at risk for inadequate intake of micronutrients, their intake was compared 
with estimated AR for the children in the present study, estimated from the Nordic adult AR. For many nutrients, extrapolation from infant and adult data is used, resulting in considerable disparities in the perceived nutritional requirements of European children ${ }^{(19)}$; therefore, the US EAR were used for comparison. The largest difference between the estimated AR for the present study and US EAR was for vitamin $\mathrm{E}$. This difference may be related to a difference in PUFA intake, as the Nordic adult AR for vitamin $\mathrm{E}$ is partly based on the average PUFA intake in the Nordic countries ${ }^{(8)}$.

More than $10 \%$ of the children did not reach the estimated AR for iodine intake, indicating that $10 \%$ of the children may be at risk of inadequate intake. Iodine deficiency has not been common in Iceland as fish and milk consumption has been high; this, however, seems to be changing. Children reaching the FBDG on fish or milk had a mean intake of iodine above or close to the Nordic RI. A significant step to equalise children's opportunity for a nutritious meal during the school day was undertaken when it was decided in the autumn of 2005 that all elementary schools in Reykjavik should serve a warm meal at lunch time, although facilities and other factors affecting the quality of the meals may still be improved. The Public Health Institute has implemented FBDG for the school canteens $^{(34)}$, e.g. fish should be served at least twice a week, and fruits or vegetables should be part of the meal every day. Water is served with the meal in all schools, but children can have milk with the meal in some schools (in two of the six schools in the present study). Most of the children in the present study participated in the school meals.

The recommendations for vitamin D intake in Iceland are among the highest in Europe ${ }^{(35)}$. The most commonly used vitamin D supplement in Iceland is fish-liver oil. The mean vitamin $D$ intake of the children reaching the FBDG, taking fish-liver oil, was close to the Icelandic RI. In the present study, $41 \%$ of the children fulfilled the recommendation to use fish-liver oil, which is similar to what was found in a recent study of diet among 6-yearold children in Iceland, assessed by weighed food records, where the frequency of fish-liver oil consumption or use of another vitamin D supplement was $40 \%{ }^{(11)}$. Values for average vitamin $\mathrm{D}$ requirements have not been established, but the median is less than two-thirds of the $\mathrm{RI}$, indicating that there is a large group of 7 -year-old children with a potential risk of deficient intake. Boys had higher intake of fish-liver oil than girls, therefore more girls are potentially at risk of deficient intake of vitamin D than boys. A similar gender difference in the intake of vitamin D was seen in a study of the diet of 9-year-olds; the mean intake for boys was $4.7 \mu \mathrm{g}$ and for girls, $2 \cdot 8 \mu \mathrm{g}^{(12)}$. The percentage of children taking fish-liver oil is higher among preschool children ${ }^{(36)}$, which may at least partly be explained by the tradition of serving fishliver oil with the breakfast in kindergartens. Vitamin D deficiency has not been detected among Icelandic children in recent decades, but the use of vitamin D supplements in schoolchildren needs to be increased, especially in girls as they seem to have lower intake. To increase intake among children, it is important to give their parents detailed recommendations on vitamin D intake for children and ensure compliance with the RI.

The purpose of FBDG is to educate the population and guide national food and nutrition policies as well as the food industry ${ }^{(1,2)}$. Thus the FBDG should help the population reach the nutrient recommendations. Changes in FBDG have been shown to affect the diet of Icelandic children. A study on infant nutrition, performed in 19951997, revealed low iron status and high protein intake, and showed that iron-status indices were negatively associated with cow's milk consumption ${ }^{(37,38)}$. The Icelandic recommendations for diet in infancy were consequently revised. A study on infant nutrition, performed in 2005-2007, to investigate the effects of the new recommendations showed that the diet in infancy and infants' iron status had improved (I Thorsdottir, AV Thorisdottir and GI Palsson, unpublished results). As changes in recommendations had an effect on the diet in infancy, effective implementation of the FBDG for schoolchildren might affect their diet. Some of these changes may have to involve the food industry, e.g. to increase consumption of wholemeal breads as most of the breads on the market use more refined meal than recommended. School-based interventions may be used to implement the FBDG. An intervention should aim at both environmental factors, like availability, and personal factors. Personal factors that have been to found to be related to fruit and vegetable intake among children, e.g. preferences, liking, self-efficacy and knowledge $^{(27)}$, may also be related to the intake of other foods.

\section{Conclusion}

Fruit, vegetable, fish and dairy products, as well as vitamin D supplements, need to be increased in 7-year-old children's diet to reach the FBDG and the reference values for nutrient intake. Dietary changes to increase the quality of fat and carbohydrate are needed as well.

\section{Acknowledgements}

The study was supported by research grants from the Eimskip Fund of the University of Iceland, Rannís-The Icelandic Centre for Research and Brim Seafood. There is no conflict of interest. A.G.K. worked on the data collection, calculations and statistical analysis and writing of the paper. I.T. designed the study, and worked on the interpretation of the results and writing of the paper. The authors thank the children and their parents for their participation and the nutritionists Svandis Erna Jonsdottir and Bryndis Elfa Gunnarsdottir for their work on data entering and coding the dietary data. 


\section{References}

1. World Health Organization (2004) Global strategy on diet, physical activity and health. World Health Assembly Resolution 57.17. http://www.who.int/gb/ebwha/pdf_files/ WHA57/A57_R17-en.pdf (accessed September 2008).

2. Keller I \& Lang T (2008) Food-based dietary guidelines and implementation: lessons from four countries - Chile, Germany, New Zealand and South Africa. Public Health Nutr 11, 867-874.

3. World Health Organization (1998) Obesity: Preventing and Managing the Global Epidemic. Report of a WHO consultation, Geneva, 3-5 June 1997. WHO/NUT/98.1. Geneva: WHO.

4. Ogden CL, Carroll MD, Curtin LR, McDowell MA, Tabak CJ \& Flegal KM (2006) Prevalence of overweight and obesity in the United States, 1999-2004. JAMA 295, 1549-1555.

5. Gunnarsdottir I \& Thorsdottir I (2003) Relationship between growth and feeding in infancy and body mass index at the age of 6 years. Int J Obes Relat Metab Disord 27, 1523-1527.

6. Johannsson E, Arngrimsson SA, Thorsdottir I \& Sveinsson T (2006) Tracking of overweight from early childhood to adolescence in cohorts born 1988 and 1994: overweight in a high birth weight population. Int J Obes (Lond) 30, 1265-1271.

7. Krause E \& Desjeux JF (2004) Summary report ILSI Europe Workshop: Nutrition in children and adolescents in Europe: what is the scientific basis? Br J Nutr 92, S75-S82.

8. Nordic Council of Ministers (2004) Nordic Nutrition Recommendations 2004: Integrating Nutrition and Physical Activity, 4th ed., Nord 2004:13. Copenhagen: Nordic Council of Ministers.

9. The Public Health Institute of Iceland (2006) Recommendations on diet and nutrients for adults and children from 2 years of age (in Icelandic). http://www.lydheilsustod.is/ media/manneldi/utgefid//mataraedi-lowres.pdf (accessed December 2008).

10. Steingrimsdottir L, Gunnarsson O, Indridason OS, Franzson L \& Sigurdsson G (2005) Relationship between serum parathyroid hormone levels, vitamin D sufficiency, and calcium intake. JAMA 294, 2336-2341.

11. Thórsdóttir I \& Gunnarsdóttir I (2005) Vitamin D in nutrition of young Icelandic children (in Icelandic). Laeknabladid 91, 581-586.

12. Thorsdottir I \& Gunnarsdottir I (2006) The diet of Icelandic 9- and 15-year-old children and adolescents. Dietary Survey of the Unit for Nutrition Research 2002-2003 (in Icelandic). Reykjavik: Public health Institute and Unit for Nutrition Research.

13. Yngve A, Wolf A, Poortvliet E et al. (2005) Fruit and vegetable intake in a sample of 11-year-old children in 9 European countries. The Pro Children Cross-sectional Survey. Ann Nutr Metab 49, 236-245.

14. Royo-Bordonada MA, Gorgojo L, Martín-Moreno JM, Garcés C, Rodríguez-Artalejo F, Benavente M, Mangas A \& de Oya M; Investigators of the Four Provinces Study (2003) Spanish children's diet: compliance with nutrient and food intake guidelines. Eur J Clin Nutr 57, 930-939.

15. Birch LL \& Fisher JO (1998) Development of eating behaviors among children and adolescents. Pediatrics 101, 539-549.

16. Lien N, Lytle LA \& Klepp KI (2001) Stability in consumption of fruit, vegetables, and sugary foods in a cohort from age 14 to age 21. Prev Med 33, 217-226.

17. Bingham SA (1994) The use of 24-h urine samples and energy expenditure to validate dietary assessments. $\mathrm{Am} \mathrm{J}$ Clin Nutr 59, 227S-231S.

18. Cole TJ, Bellizzi MC, Flegal KM \& Dietz WH (2000) Establishing a standard definition for child overweight and obesity worldwide: international survey. BMJ320, 1240-1243.

19. Prentice A, Branca F, Decsi T, Michaelsen KF, Fletcher RJ, Guesry P, Manz F, Vidailhet M, Pannemans D \& Samartín S
(2004) Energy and nutrient dietary reference values for children in Europe: methodological approaches and current nutritional recommendations. Br J Nutr 92, S83-S146.

20. Food and Nutrition Board, Institute of Medicine (1998) Dietary Reference Intakes for Thiamin, Riboflavin, Niacin, Vitamin $B_{6}$, Folate, Vitamin $B_{12}$, Pantothenic Acid, Biotin and Cholin. Washington, DC: National Academic Press.

21. Food and Nutrition Board, Institute of Medicine (2000) Dietary Reference Intakes for Vitamin C, Vitamin E, Selenium and Carotenoids. Washington, DC: National Academic Press.

22. Food and Nutrition Board, Institute of Medicine (2006) The Dietary Reference Intakes: The Essential Guide to Nutrient Requirements. Washington, DC: National Academic Press.

23. Livingstone MB, Robson PJ \& Wallace JM (2004) Issues in dietary intake assessment of children and adolescents. Br J Nutr 92, S213-S222.

24. Livingstone MB \& Black AE (2003) Markers of the validity of reported energy intake. J Nutr 133, 895S-920S.

25. Glynn L, Emmett P \& Rogers I; ALSPAC Study Team (2005) Food and nutrient intakes of a population sample of 7-yearold children in the South-West of England in 1999/2000 - what difference does gender make? J Hum Nutr Diet 18, 7-19.

26. Lambert J, Agostoni C, Elmadfa I, Hulshof K, Krause E, Livingstone B, Socha P, Pannemans D \& Samartín S (2004) Dietary intake and nutritional status of children and adolescents in Europe. Br J Nutr 92, S147-S211.

27. Kristjansdottir AG, Thorsdottir I, De Bourdeaudhuij I, Due P, Wind M \& Klepp KI (2006) Determinants of fruit and vegetable intake among 11-year-old schoolchildren in a country of traditionally low fruit and vegetable consumption. Int J Behav Nutr Phys Act 3, 41.

28. Thorsdottir I, Gunnarsdottir I, Ingolfsdottir SE \& Palsson G (2006) Fruit and vegetable intake: vitamin $C$ and $\beta$-carotene intake and serum concentrations in six-year-old children and their parents. Scand J Food Nutr 50, 71-76.

29. Thane CW, Jones AR, Stephen AM, Seal CJ \& Jebb SA (2005) Whole-grain intake of British young people aged 4-18 years. Br J Nutr 94, 825-831.

30. Lang R, Thane CW, Bolton-Smith C \& Jebb SA (2003) Consumption of whole-grain foods by British adults: findings from further analysis of two national dietary surveys. Public Health Nutr 6, 479-484.

31. Cleveland LE, Moshfegh AJ, Albertson AM \& Goldman JD (2000) Dietary intake of whole grains. J Am Coll Nutr 19, 331S-338s.

32. Øverby NC, Lillegaard IT, Johansson L \& Andersen LF (2004) High intake of added sugar among Norwegian children and adolescents. Public Health Nutr 7, 285-293.

33. Haines PS, Hama MY, Guilkey DK \& Popkin BM (2003) Weekend eating in the United States is linked with greater energy, fat, and alcohol intake. Obes Res 11, 945-949.

34. The Public Health Institute of Iceland (2005) Guide for the School-Canteens (in Icelandic). http://www.lydheilsustod. is/media/manneldi/fraedsla/Handbok_skolamotuneyti.pdf (accessed December 2008).

35. Doets EL, de Wit LS, Dhonukshe-Rutten RA et al. (2008) Current micronutrient recommendations in Europe: towards understanding their differences and similarities. Eur J Nutr 47, 17-40.

36. Eysteinsdottir T, Gunnarsdottir I \& Thorsdottir I (2008) The diet of 3- and 5-year-old children (in Icelandic). Reykjavik: Unit for Nutrition Research.

37. Thorsdottir I, Gunnarsson BS, Atladottir H, Michaelsen KF \& Palsson G (2003) Iron status at 12 months of age - effects of body size, growth and diet in a population with high birth weight. Eur J Clin Nutr 57, 505-513.

38. Gunnarsson BS, Thorsdottir I \& Palsson G (2004) Iron status in 2-year-old Icelandic children and associations with dietary intake and growth. Eur J Clin Nutr 58, 901-906. 